\title{
Four Excitatory Postsynaptic Ionotropic Receptors Coactivated at the Motoneuron-Renshaw Cell Synapse
}

\author{
Boris Lamotte d'Incamps ${ }^{1}$ and Philippe Ascher ${ }^{2}$ \\ ${ }^{1}$ Laboratoire de Neurophysique et Physiologie and ${ }^{2}$ Laboratoire de Physiologie Cérébrale, Centre National de la Recherche Scientifique (CNRS), Université \\ Paris Descartes, 75006 Paris, France
}

\begin{abstract}
Renshaw cells (RCs) are spinal interneurons excited by collaterals of the axons of motoneurons (MNs). They respond to a single motoneuronal volley by a surprisingly long (tens of milliseconds) train of action potentials. We have analyzed this synaptic response in spinal cord slices of neonatal mice in light of recent observations suggesting that the MN axons release both acetylcholine and glutamate. We found that the RC synaptic current involves four components of similar amplitudes mediated by two nicotinic receptors (nAChRs, tentatively identified as $\alpha_{7}$ homomers and $\alpha_{4} \beta_{2}$ heteromers) and two glutamate receptors (AMPARs and NMDARs). The decay time constants of the four components cover a wide range: from $3.6 \pm 2.2 \mathrm{~ms}\left(\alpha_{7} \mathrm{nAChRs}\right)$ to $54.6 \pm 19.5 \mathrm{~ms}$ (NMDARs, at $-45 \mathrm{mV}$ ). The RC discharge can be separated into an initial doublet of high-frequency action potentials followed by later spikes with a variable latency and longer interspike intervals. The initial doublet involves the four ionotropic receptors as well as endogenous voltage-dependent conductances. The late discharge depends on NMDARs, but these receptors must be primed by the initial depolarization. The activation of the NMDARs is prolonged by the fact that their slow deactivation is further slowed by depolarization. The formation of the initial doublet is favored by hyperpolarization, whereas the late discharge is favored by depolarization. This suggests that in physiological conditions the pattern of discharge of the $\mathrm{RC}$ in response to a MN input may alternate between a phasic and a tonic response.
\end{abstract}

Key words: motoneurons; Renshaw cells; recurrent inhibition; corelease; nicotinic receptors; NMDA receptors

\section{Introduction}

The existence of the spinal inhibitory interneurons known today as the Renshaw cells (RCs) was proposed by Renshaw (1941) to explain why the antidromic activation of the axons of spinal motoneurons (MNs) inhibits a large pool of MNs. In 1946, Renshaw recorded the activity of the "predicted" interneurons and found that a single ventral root (VR) stimulation elicited a highfrequency discharge lasting tens of milliseconds. This was a landmark observation as it provided the first identification of the neuronal organization of a negative feedback loop. However, the mechanism by which a single presynaptic volley elicits a long lasting burst of impulses in the postsynaptic cell has not yet been satisfactorily explained, and was the object of our investigation.

In 1954, Eccles et al. reported that di-hydro- $\beta$-erythroidine $(\mathrm{DH} \beta \mathrm{E})$, an antagonist of nicotinic receptors (nAChRs), blocked most of the activation of the RC by the VR stimulation. They concluded that the MN-RC synapse was cholinergic. To explain

\footnotetext{
Received July 16, 2008; revised 0ct. 21, 2008; accepted Nov. 10, 2008.

This work was supported by the Action Concertée Incitative "Biologie du développement et physiologie intégrative," the Agence Nationale de la Recherche "Neurosciences," and the Association Française contre les Myopathies. We thank Tomoyuki Takahashi for showing us how to include the spinal cord in agar, Bert Sakmann for the loan of a slicer, Stéphane Dieudonné and Marco Beato for suggesting slicing in a high- $K^{+}$solution, Stephen Traynelis for help with ChanneLab, and Daniel Bertrand, Stéphane Dieudonné, Eric Krejci, Jon Johnson, Claude Meunier, Alain Marty, Peter Sargent, Stéphane Supplisson, and Daniel Zytnicki for discussions.

Correspondence should be addressed to either of the following: Boris Lamotted'Incamps, Laboratoire de Neurophysique et Physiologie, or Philippe Ascher, Laboratoire de Physiologie Cérébrale, CNRS, Université Paris Descartes, 45 rue des Saints Pères, 75006 Paris, France. E-mail: boris.lamotte-incamps@parisdescartes.fr or philippe.ascher@parisdescartes.fr. DOI:10.1523/JNEUROSCI.3311-08.2008

Copyright $\odot 2008$ Society for Neuroscience $\quad$ 0270-6474/08/2814121-11\$15.00/0
}

the long durations of both the RC train of action potentials and the underlying synaptic potential, they suggested that acetylcholine $(\mathrm{ACh})$ is not destroyed rapidly by acetylcholinesterase (AChE). However, Eccles and Jaeger (1958) soon showed that even in the absence of ACh hydrolysis, diffusion of ACh out of the synaptic cleft would be faster than the decay of the discharge. Eccles et al. (1961) then considered some ACh spillover to extrasynaptic receptors. This new hypothesis implied that extrasynaptic receptors are activated by a low concentration of $\mathrm{ACh}$, which was difficult to reconcile with the low affinity of the known nAChRs. However, it was recently reported that some recombinant nAChRs have apparent dissociation constants for ACh in the low micromolar range (Buisson et al., 1996; Zwart et al., 1998; Covernton and Connolly, 2000; Moroni et al., 2006). The slow dissociation of ACh from such receptors, if they were present on the RCs, could explain the long duration of the RC synaptic current.

A second interpretation appeared when, in 2005, Mentis et al. and Nishimaru et al. reported that, in newborn mice ( $\mathrm{P} 0-\mathrm{P} 4)$, the MN-RC synapse involves AMPARs and NMDARs in addition to nAChRs. These observations suggested to us an alternative explanation for the long duration of the RC response. Glutamate dissociates slowly from NMDARs, and the functional activation of these receptors in a quiescent neuron requires a "priming" depolarization to remove the $\mathrm{Mg}^{2+}$ block. If the activation of nAChRs were essential for the priming depolarization, one could explain both the long duration of the discharge of the RC and its sensitivity to $\mathrm{DH} \beta \mathrm{E}$. Functionally, the hypothesis that the long dura- 
tion of the RC response is due to the slow unbinding of glutamate from NMDARs predicts that the slow response will increase if the $\mathrm{RC}$ is depolarized, which would not be observed if the duration is controlled by the slow unbinding of ACh.

We have tested the two hypotheses in slices of the spinal cord of neonatal mice (P5-P10) at room temperature. In this preparation the $\mathrm{RC}$ action potential train triggered by a VR stimulation has a much lower frequency than the responses recorded in adult cats (Renshaw 1946, Eccles et al., 1954), but it has a similar long duration. This response therefore appeared as a possible model for understanding the long duration of the adult response.

\section{Materials and Methods}

Animals and slice preparation. C57B6 mice (Janvier) (P5-P10) were anesthetized with an intraperitoneal injection of $0.1 \mathrm{ml}$ of chloral hydrate $(0.2$ M) or pentobarbital $(20 \mathrm{~mm})$. An intracardiac perfusion was performed using ice-cold low- $\mathrm{Na}^{+}$Ringer (Brunel et al., 2004), containing (in mM): $\mathrm{KCl} 3, \mathrm{NaH}_{2} \mathrm{PO}_{4} 1.25$, sucrose 230, $\mathrm{NaHCO}_{3} 26, \mathrm{CaCl}_{2} 0.8, \mathrm{MgCl}_{2} 8$, glucose 25 , ascorbic acid 0.4 , and kynurenic acid 1.0, and bubbled with $95 \% \mathrm{O}_{2}$ and $5 \% \mathrm{CO}_{2}, \mathrm{pH}$ 7.4. After decapitation the laminectomy was performed at $\sim 4^{\circ} \mathrm{C}$ in the same solution. After sectioning of the roots, the cord was transferred into a $2 \%$ agar solution at $38^{\circ} \mathrm{C}$. This solution was then cooled to $4^{\circ} \mathrm{C}$ and an agar block containing the spinal cord at the adequate orientation was cut and glued in the chamber of a slicer (either a Leica S100V or a slicer constructed at the MPI for Medical Research in Heidelberg). The slices were $400 \mu \mathrm{m}$ thick. Because the MN axons exit obliquely from the spinal cord, the slices were cut obliquely $\left(45^{\circ}\right)$ relative to the axis of the spinal cord to follow as much as possible the MN axons so that the VR axons and their target RCs both had a good chance of being inside the slice. The slices were transferred into Ringer at $34^{\circ} \mathrm{C}$ for $30 \mathrm{~min}$ and then brought to room temperature.

For a fraction of the experiments, the spinal cord was dissected in the low- $\mathrm{Na}^{+}$solution but sliced in the high- $\mathrm{K}^{+}$solution described by Dugué et al. (2005). On average we found that the condition of the slices was greatly improved by this procedure. The survival rate of MNs was higher than when slicing was done in the low- $\mathrm{Na}^{+}$solution. The $\mathrm{RC}$ responses recorded in voltage clamp were indistinguishable from those recorded in slices prepared with the low- $\mathrm{Na}^{+}$solution, but the average resting potential was more negative. Probably as a result of this difference, the discharges of the RCs were shorter. The initial doublet (see Results) was nearly always present but the late discharge was sometimes absent. Concomitantly, when recording in MNs, the initial set of IPSCs (P1-P2, see Results) was always present but the wave of late IPSCs (P3, see Results) was often small.

Slices were visualized using a $40 \times$ water-immersion objective (Axioskop, Carl Zeiss) and infrared optics (illumination filter $750 \pm 50$ $\mathrm{nm}$; CCD camera). The slices used were those containing a VR of sufficient length to be mounted on a suction stimulation electrode.

Electrophysiology. All experiments were performed at room temperature $\left(18-24^{\circ} \mathrm{C}\right)$. The recording chamber was continuously perfused at a rate of $1-2 \mathrm{ml} / \mathrm{min}$ with a solution containing (in $\mathrm{mm}$ ): $\mathrm{NaCl} 130, \mathrm{KCl}$ 2.5, $\mathrm{CaCl}_{2} 2, \mathrm{MgCl}_{2} 1, \mathrm{NaH}_{2} \mathrm{PO}_{4} 1.3, \mathrm{NaHCO}_{3} 26$, glucose 25 , and ascorbic acid 0.4 , bubbled with $95 \% \mathrm{O}_{2}$ and $5 \% \mathrm{CO}_{2}(\mathrm{pH} 7.4$ ).

RCs were looked for in the lamina VII and IX of the ventral horn. Most of them were found close to the region where the axons of the MNs converge to make two to three axon bundles. In these regions, there are few neurons and the RCs stand out, characterized by their size and their capacitance. The cells were approximately ellipsoidal, and the average lengths of the two axes were $18 \pm 3$ and $13 \pm 2 \mu \mathrm{m}$ (mean $\pm \mathrm{SD}, n=30$ ). The mean capacitance was $53 \pm 23 \mathrm{pF}(n=32)$. However the final identification was based on the fact that an antidromic stimulation of the VR evoked the characteristic synaptic current analyzed in the results section.

MNs were identified by their location and their characteristic large size. We only analyzed MNs in which the VR stimulation elicited a train of IPSCs. In approximately half of these MNs an antidromic active current preceded the train of IPSCs. This current rapidly subsided as QX314 diffused into the cell, but a residual current often persisted. The remaining neurons were probably MNs, the axons of which were not in the stimulated rootlet, although some may have been spinal border cells from the ventral spinocerebellar tract, which resemble MNs in position and size, and of which some receive recurrent inhibition (Lindström and Schomburg, 1973). The train of IPSCs was similar in MNs with and without an antidromic current. This is expected from previous analyses of the recurrent IPSCs, which have shown that RCs not only inhibit the MNs that excite them, but also neighboring MNs (Renshaw 1946, Schneider and Fyffe 1992).

When RCs and MNs were recorded in the whole-cell configuration, patch pipettes had an initial open-tip resistance of 4-6 M $\Omega$. All internal solutions had osmolarities of 285-295 mOsm/L. Depending on the experiment, we used $\mathrm{Cs}^{+}$-based or $\mathrm{K}^{+}$-based internal solutions.

The $\mathrm{Cs}^{+}$-based solution contained (in $\mathrm{mM}$ ): Cs-gluconate 125, QX$314 \mathrm{Cl}$ 5, HEPES 10, EGTA 10, $\mathrm{CaCl}_{2} 1, \mathrm{Mg}$-ATP 4, and Na-GTP 0.4, pH adjusted to 7.3 with $\mathrm{CsOH}$. The liquid junction potential was $-15 \mathrm{mV}$. Except where indicated, recordings were made at $-45 \mathrm{mV}$ (after correction for the junction potential). At this potential one could observe spontaneous synaptic outward currents that could be blocked by GABA and glycine antagonists. The reversal potential of these IPSCs was close to $-60 \mathrm{mV}$.

A K ${ }^{+}$-based solution without QX-314 was used to analyze, both in voltage clamp and current clamp, the RC responses to VR stimulation in conditions approximating as much as possible the physiological conditions. This solution contained K-gluconate 125, HEPES 10, EGTA 1, $\mathrm{CaCl}_{2}$ 0.1, Mg-ATP 4, Na-GTP 0.4, pH adjusted to 7.3 with $\mathrm{KOH}$. Values of the membrane potential were corrected for the liquid junction potential $(-15 \mathrm{mV})$.

VRs were stimulated by means of a glass pipette with a tip size adapted to the diameter of the rootlet $(40-170 \mu \mathrm{m})$ and filled with Ringer saline. The stimulus intensity was varied between 10 and $100 \mathrm{~V}$; the stimulus duration was varied between 50 and $300 \mu$ s. Bipolar pulses were used in all cases. Stimulation frequency was $0.1 \mathrm{~Hz}$.

As described in Results, the RC response observed at $-45 \mathrm{mV}$ is an inward synaptic current in which four components can be separately suppressed by the four specific antagonists 2,3-dioxo-6-nitro-1,2,3,4tetrahydrobenzo(f)quinoxaline-7-sulfonamide (NBQX) (2 $\mu \mathrm{M}), \mathrm{D}-2-$ amino-5-phosphonovaleric acid (D-APV) $(50 \mu \mathrm{M}), \mathrm{DH} \beta \mathrm{E}(3 \mu \mathrm{M})$ and methyllycaconitine (MLA) (10 nM). When a small inward current persisted after adding these four antagonists, it could usually be abolished by increasing the concentration of $\mathrm{DH} \beta \mathrm{E}$ to $10 \mu \mathrm{M}$ or adding mecamylamine (MEC) at a concentration $(50 \mu \mathrm{M})$ where MEC acts as a nonspecific nicotinic antagonist (see supplemental Fig. $1 A$, available at www.jneurosci.org as supplemental material). In a few cases, a shortlatency current persisted even after adding MEC. This current was inward at all potentials between $-60 \mathrm{mV}$ and $+45 \mathrm{mV}$, and appeared as a "spikelet," which may reflect the antidromic action potentials of the surrounding MN axons detected either as a field response or as an electrotonic response transmitted through gap junctions.

The MN response to the VR stimulation consisted of a train of recurrent IPSCs that could be partially blocked by either strychnine $(1 \mu \mathrm{M})$ or gabazine $(3 \mu \mathrm{M})$, and completely blocked by a combined application of these compounds (data not shown). Similar observations using strychnine and bicuculline in newborn rats led Schneider and Fyffe (1992) to conclude that the IPSCs involve both GABA and glycine receptors. As will be shown (see Results), the recurrent IPSCs were suppressed by the combined application of cholinergic and glutamatergic blockers. In some MNs, we detected a short-latency monophasic outward synaptic current. This current was blocked by the combined application of gabazine and strychnine, but was insensitive to either cholinergic or glutamatergic blockers; it thus appeared due to the direct activation of inhibitory interneurons. When such a current was detected, the experiment was discarded.

We also observed the occasional presence in MNs of inward currents supported by either ACh receptors or glutamate receptors and corresponding to excitatory MN-MN connections (Schneider and Fyffe, 1992; Mentis et al., 2005; Nishimaru et al., 2005). These currents could be observed in isolation by bringing the membrane potential to $-60 \mathrm{mV}$, the reversal potential for the inhibitory synaptic currents. When present, 
A

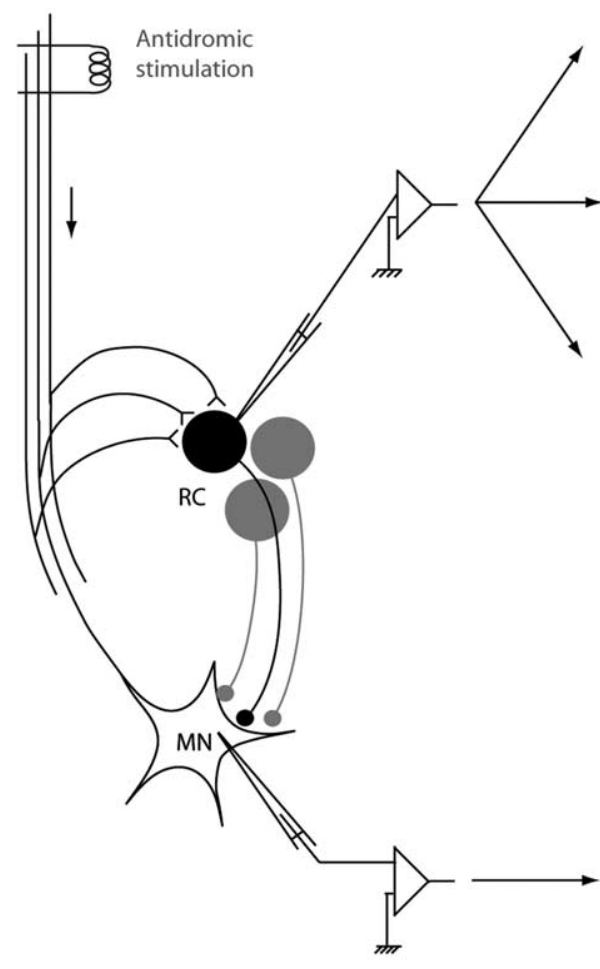

$\mathrm{B}_{1}$
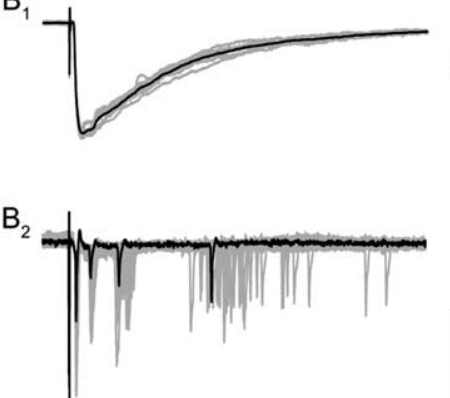

c

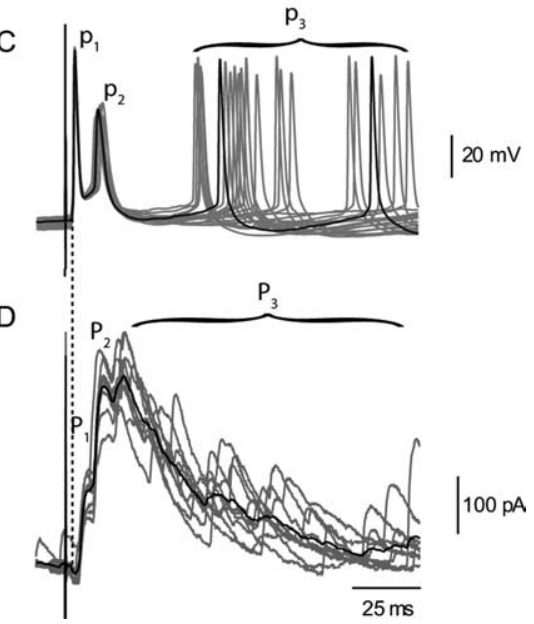

Figure 1. $\mathrm{RC}$ responses and MN response to a single volley on the VR. $\boldsymbol{A}$, Schematic organization of recurrent inhibition. $\boldsymbol{B}-\boldsymbol{D}$, Four configurations used to analyze $R$ C responses. $B 1$, RC synaptic current recorded in voltage clamp at $-45 \mathrm{mV}$. B2, Cell-attached recording of the $\mathrm{RC}$ shown in $\mathrm{B} 1$ before break-in. $\boldsymbol{C}$, Current-clamp recording of a $\mathrm{RC}$ response in a different cell. $\boldsymbol{D}$, Voltage-clamp recording from a MN held at $-45 \mathrm{mV}$. Inhibitory synaptic currents are outward ( $E_{\mathrm{Cl}}$ was at $-60 \mathrm{mV}$ ). The gray traces correspond to individual records taken at 10 sintervals. The black traces are selected individual records in $B 2$ and $C$, and averages of the 10 gray traces in $\boldsymbol{B} 1$ and $\boldsymbol{D}$. The recurrent IPSCs in the MNs were separated into two early peaks (P1 and P2) and a late discharge labeled P3 (Schneider and Fyffe, 1992). The action potentials of the RC were correspondingly separated into an early doublet (p1, p2) and a late discharge $\mathrm{p} 3$. For a quantitative characterization of $\mathrm{P} 3$ and $\mathrm{p} 3$, we arbitrarily selected the interval between 50 and $100 \mathrm{~ms}$ after the VR stimulation and evaluated $\mathrm{P} 3$ as the mean outward current during this interval (see Fig. 5 ) and $\mathrm{p} 3$ as the mean number of action potentials recorded in the RC cell during this interval (see Fig. 6 and supplemental Fig. 2, available at www.jneurosci.org as supplemental material).

these currents were much smaller than the outward currents at $-45 \mathrm{mV}$ (the potential at, which we made a large part of our experiments) and their contribution could be eliminated by recording at $0 \mathrm{mV}$.

NBQX, D-APV, and gabazine (SR 95531) were purchased from Tocris and Ascent. QX-314 chloride was from Alomone. All the other chemicals were from Sigma.

Data acquisition and analysis. A HEKA EPC-9 amplifier was used for data acquisition. Whole-cell recordings were digitized at $10 \mathrm{kHz}$ and filtered at $3 \mathrm{kHz}$. The series resistance $\left(R_{\mathrm{s}}\right)$ compensation implemented in the HEKA programs was applied in some experiments but was never pushed to its limits because it tended to increase the stimulation artifact and obscured the measurement of the rising phase of the RC response. Therefore, in most cases in which $R_{\mathrm{s}}$ compensation was important for the evaluation of the time constants of the rise and decay of the synaptic currents, and in particular the fast synaptic currents mediated by AMPARs and by MLA-sensitive nAChRs, we corrected a posteriori for the filtering introduced by the series resistance, using the algorithm of Traynelis (1998), which allows to deduce the "true" current trace from the filtered one provided one knows the series resistance, the capacitance of the cell, the membrane resistance, and the shape of the $I-V$ relation. For AMPA currents, which have a linear $I-V$ relation (see Results), we used the Traynelis correction implemented into an Igor macro by Erwin Neher (Max Planck Institute for Biophysical Chemistry, Göttingen, Germany). For MLA-sensitive currents, which show a marked inward rectification (see Results), we used the algorithm implemented by Stephen
Traynelis (Emory University, Atlanta, GA) in the Channelab version 2 program available from Synaptosoft. Records were analyzed with the Igor Pro software Neuromatic.

The rise times of the response, $\tau_{\mathrm{p}}$, were measured as the rise times between $20 \%$ and $80 \%$ of the peak response. The decay time constants, $\tau_{\mathrm{d}}$, were measured by fitting a single exponential either on the decay of the response isolated by addition of blockers of the other responses, or on the decay of the component calculated by subtracting the records taken before and after addition of a specific antagonist. In the case of the NMDAR-mediated responses we used a double exponential fit and calculated a weighted decay time $\tau_{\mathrm{w}}=\left(A_{1} \times \tau_{1}+A_{2} \times\right.$ $\left.\tau_{2}\right) /\left(A_{1}+A_{2}\right)$, where $A_{1}$ and $A_{2}$ are the relative amplitudes of the two components with time constants $\tau_{1}$ and $\tau_{2}$. Data in Results are expressed as mean $\pm \mathrm{SD}$.

The $I-V$ relations for NMDARs and $\mathrm{nAChRs}$ (see Figs. 3, 4) were fitted by using a simplified Woodhull (1973) model, assuming that the rectification of the NMDAR-mediated current was entirely due to blockade by external $\mathrm{Mg}^{2+}$ and that the inward rectification of the nicotinic currents was entirely due to blockade by internal $\mathrm{Mg}^{2+}$ despite the fact that it is known that the inward rectification also involves other factors. When one assumes that $\mathrm{Mg}^{2+}$ cannot cross the channel, the Woodhull equations contain only two sets of adjustable variables, $\left[\left(b_{-1} / b_{1}\right) /\left[\mathrm{Mg}^{2+}\right]\right]$ and $\delta .\left(b_{-1} / b_{1}\right)$ is the dissociation constant of $\mathrm{Mg}^{2+}$ at the binding site at $0 \mathrm{mV}$, which we will note $K(0)$. $\delta$ represents the fraction of the field seen by $\mathrm{Mg}^{2+}$ at its binding site. In the case of the NMDARmediated current, $\left[\mathrm{Mg}^{2+}\right]$ is the extracellular concentration of free $\mathrm{Mg}^{2+},\left[\mathrm{Mg}^{2+}\right]_{0}$, which is known to be $1 \mathrm{~mm}$, and the $I-V$ curve was characterized by the values of $K(0)$ and $\delta$. In the case of the nAChR-mediated currents $\left[\mathrm{Mg}^{2+}\right]$ is the internal concentration of free $\mathrm{Mg}^{2+}$, $\left[\mathrm{Mg}^{2+}\right]_{\mathrm{i}}$, and is not known exactly because the total $\mathrm{Mg}^{2+}(4 \mathrm{mM})$ is partially complexed by ATP. Thus, in the case of the nicotinic currents, the rectification was characterized by the values of the ratio $K(0) /\left[\mathrm{Mg}^{2+}\right]_{\mathrm{i}}$ and of $\delta$.

\section{Results}

\section{The $\mathrm{RC}$ response to the VR stimulation}

We have analyzed the $\mathrm{RC}$ response to a single shock applied on a $\mathrm{VR}$ by recording from the $\mathrm{RC}$ or by recording the RC-activated IPSCs in the MNs. The stimulation of a VR activates a large number of axons terminating on a given RC. The data of Nishimaru et al. (2005) suggest that the synaptic current produced by a single motoneuron is on the order of $-5 \mathrm{pA}$ at $-45 \mathrm{mV}$, in, which case the mean value of the responses that we studied (around $-100 \mathrm{pA}$ at $-45 \mathrm{mV}$ ) corresponds to the stimulation of $\sim 20$ axons. Similarly, each MN receives inputs from many RCs (Fig. 1).

The RC synaptic current recorded in voltage clamp, in the whole-cell mode, is a fast-rising, slowly decaying current (Fig. 1B1). This current triggers trains of action potentials, which could be observed directly, either in the cell-attached mode or in the whole-cell mode (Fig. 1B2,C). In neonatal rats or mice, the train consists of only a few spikes, in general 3-7 (Schneider and Fyffe, 1992; Mentis et al., 2005; Nishimaru et al., 2005, Alvarez 

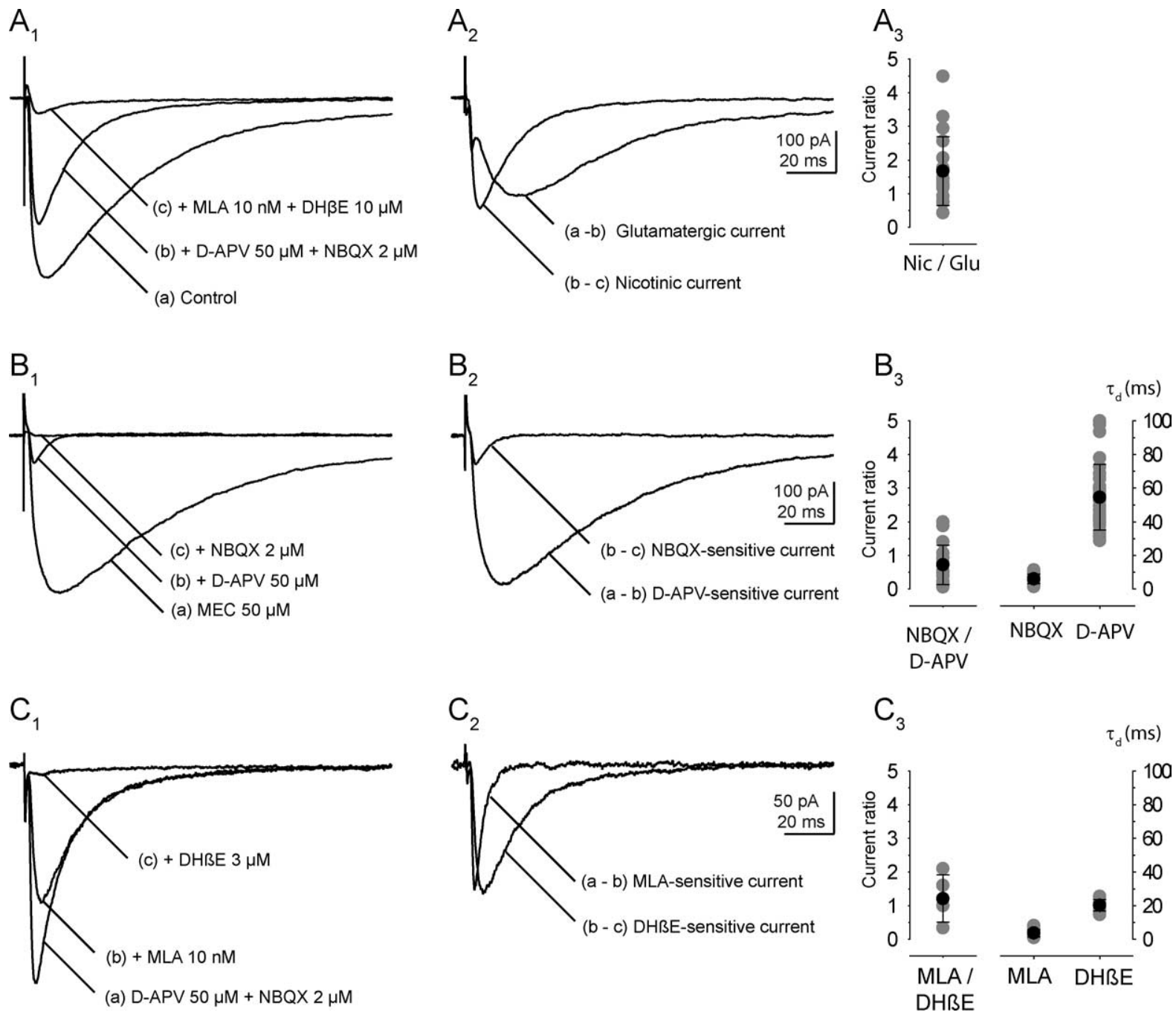

Figure 2. The four components of the RC synaptic current evoked by a VR stimulation. $\boldsymbol{A} 1-\mathbf{A 3}$, Glutamatergic and cholinergic components of the RC synaptic current. $\boldsymbol{A 1}$, The current was recorded at $-45 \mathrm{mV}$. a, Control; b, after application of D-APV $(50 \mu \mathrm{M})$ and NBQX (2 $\mu \mathrm{M})$; c, after addition of MLA (10 nM) and DH $\beta \mathrm{E}(10 \mu \mathrm{M})$. A2, The glutamatergic component of the EPSC, computed by subtraction $(a-b)$, is superimposed on the nicotinic current $(b-c)$. A3, Ratio of the cholinergic current over the glutamatergic current (gray: individual values, black: mean and SD, $n=19)$. B1-B3, The two components of the glutamatergic current. $\boldsymbol{B}$ 1, The glutamatergic current (a) had been isolated by applying a nonspecific nicotinic antagonist (MEC $50 \mu \mathrm{M}$ ). The application of D-APV $(50 \mu \mathrm{M}$ ) leaves a residual current (b), which is completely eliminated by NBQX (c). B2, The AMPAR-mediated current (b-c) is superimposed on the NMDAR-mediated current $(a-b) . B 3$, Ratio of the AMPAR-mediated current over the NMDAR-mediated current (gray: individual values, black: mean and SD, $n=$ 17), and of the mean values of the decay time constants of the two currents at $-45 \mathrm{mV}$ (AMPAR: $n=18$; NMDAR: $n=29)$. C1-C3, The two components of the nicotinic current. C1, The nicotinic current (a) had been isolated by applying D-APV $(50 \mu \mathrm{M})$ and NBQX (2 $\mu \mathrm{M})$. The application of MLA (10 nM) left a residual current (b), which was eliminated by DH $\beta E(3 \mu \mathrm{M})$ (c). C2, The MLA-sensitive current $(b-c)$ is superimposed on the $\mathrm{DH} \beta \mathrm{E}$-sensitive current $(\mathrm{a}-\mathrm{b})$. C3, Ratio of the MLA-sensitive current (probably mediated by $\alpha_{7}$ homomeric receptors) over the $\mathrm{DH} \beta \mathrm{E}$-sensitive current (probably mediated by $\alpha_{4} \beta_{2}$ heteromeric receptors; $n=5$ ), and of the mean values of the decay time constants of the two currents at $-45 \mathrm{mV}(n=$ 10 for both currents).

and Fyffe, 2007). The first two spikes of the train usually formed a doublet with a stable latency, while the later spikes occurred with a variable latency.

This pattern of response of the $\mathrm{RC}$ was also visible in the trains of IPSCs recorded in MNs after a VR stimulation (Fig. 1D). Schneider and Fyffe (1992) labeled P1 and P2 the first two peaks of the synaptic train (time-locked with the stimulus), and P3 the late component. Using a similar notation we labeled p1 and p2 the first two action potentials of the RC discharge, and p 3 the late train (Fig. 1C). The comparison of the $\mathrm{MN}$ records with those of a single RC indicates that $\mathrm{P} 3$ results from the asynchronous summation of the IPSCs triggered by the late spikes (p3) of many RCs. P3 can thus be used to characterize the ensemble behavior of these late spikes in a population of RCs.

\section{The RC synaptic current has both glutamatergic and} cholinergic components

The glutamatergic component of the RC synaptic current observed by Mentis et al. (2005) and Nishimaru et al. (2005) in newborn mice ( $\mathrm{P} 0-\mathrm{P} 4)$ was readily confirmed in our slices prepared from older mice (P5-P10). The application of NBQX and $\mathrm{D}-\mathrm{APV}$ reduced and shortened the synaptic current (Fig. $2 A 1, A 2$ ). The time constant of the current decay (measured at $-45 \mathrm{mV}$ ) decreased from $61.9 \pm 29.2 \mathrm{~ms}$ (weighted time constant, $n=15$ ) to $16.2 \pm 6.2 \mathrm{~ms}$ (single exponential, $n=18$ ). The current remaining after addition of $\mathrm{D}-\mathrm{APV}$ and NBQX was blocked by the combined addition of two nicotinic antagonists, MLA $(10 \mathrm{nM})$ and $\mathrm{DH} \beta \mathrm{E}(10 \mu \mathrm{M})$. The ratio of the peak amplitudes of the nicotinic response over that of the glutamatergic 
A
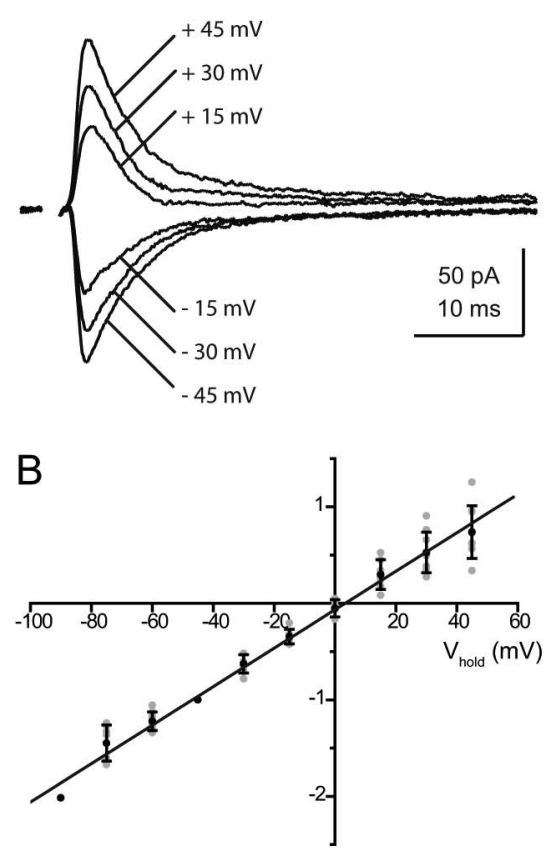

Figure 3. Voltage dependence of the two glutamatergic components of the RC synaptic current. The total glutamatergic current mediated by AMPARs and NMDARs was first isolated by application of DH $\beta E(3 \mu \mathrm{M})$ and MLA (10 nM). The AMPAR and NMDAR components were then isolated using either D-APV $(50 \mu \mathrm{M}, \boldsymbol{A}, \boldsymbol{B})$ or NBQX $(2 \mu \mathrm{m}, \boldsymbol{C}, \boldsymbol{D})$. $\boldsymbol{A}, \boldsymbol{B}, \mathrm{AMPAR}$-mediated currents. $\boldsymbol{A}$, Records from one experiment (mean of $4-10$ traces) at six different potentials ( $-45 \mathrm{mV},-30 \mathrm{mV},-15 \mathrm{mV},+15 \mathrm{mV},+30$ $\mathrm{mV},+45 \mathrm{mV}$ ). The time constants of decay varied between $2.3 \mathrm{~ms}$ and $4.9 \mathrm{~ms}$. $\boldsymbol{B}, \mathrm{I}-V$ relation of the peak currents measured in nine experiments, normalized to the value at $-45 \mathrm{mV}$. In four of the nine experiments the internal solution contained $100 \mu \mathrm{m}$ spermine. C, D, NMDAR-mediated currents. C, Records from one experiment (mean of 10 traces) at 10 different potentials from $-90 \mathrm{mV}$ to $+45 \mathrm{mV}$, steps of $15 \mathrm{mV})$. The weighted time constants of decay varied between $42.7 \pm 11.4 \mathrm{~ms}(-60 \mathrm{mV})$ to $110.6 \pm 31.4 \mathrm{~ms}(+45 \mathrm{mV})$. $\boldsymbol{D}, \mathrm{I}-\mathrm{V}$ relation of the peak currents measured in six experiments, normalized to the value at +30 $\mathrm{mV}$. The continuous lines represent a fit of the $I-V$ relations using a Woodhull model (1973). The values of the parameters are given in Results. In $\boldsymbol{B}$ and $\boldsymbol{D}$, the individual data points are in gray, and the mean values and error bars in black.

The two components of the RC glutamatergic current

The glutamatergic components of the synaptic current were characterized after blockade of the nAChRs, either by MLA $(10 \mathrm{nM})$ and $\mathrm{DH} \beta \mathrm{E}(3 \mu \mathrm{M})$ or by MEC (50 $\mu \mathrm{M})$. The AMPAR-mediated current was isolated by blocking the NMDARs by D-APV $(50 \mu \mathrm{M})$ (Figs. 2B, 3A). The NMDAR-mediated current was isolated by blocking the AMPARs by NBQX $(2 \mu \mathrm{M})$ (Fig. 3C).

The AMPAR-mediated current had a fast rise and a fast decay. The mean rise time, $\tau_{\mathrm{p}},(20 \%$ to $80 \%)$, was $0.9 \pm 0.5 \mathrm{~ms}$ $(n=18)$. The time constant of the decay, $\tau_{\mathrm{d}}$, measured at $-45 \mathrm{mV}$, had a mean value of $6.0 \pm 2.8 \mathrm{~ms}(n=18)$ (Fig. 2 B3). It did not show any voltage dependence (Fig. $3 A)$ even if spermine $(100 \mu \mathrm{M})$ was added to the intracellular solution. The ratio of the time constants measured at $-60 \mathrm{mV}$ and $+45 \mathrm{mV}$ was $\tau_{\mathrm{d}}(-60) / \tau_{\mathrm{d}}(+45)=$ $0.98 \pm 0.22(n=8)$. The $I-V$ relation of the peak AMPAR-mediated current was linear (Fig. 3B), which suggests that the AMPARs contain a GluR2 subunit and have a low $\mathrm{Ca}^{+}$permeability (Hollmann and Heinemann, 1994).

The NMDAR-mediated response had a slow rise and a slow decay. The mean value of $\tau_{\mathrm{p}}$ was $4.7 \pm 1.5 \mathrm{~ms}(n=26)$. The weighted time constant of the decay at $-45 \mathrm{mV}$ was $\tau_{\mathrm{w}}=54.6 \pm 19.5 \mathrm{~ms}(n=29)$ (Fig. 2B3). This time constant increased when the cell was depolarized, and the slowing was particularly strong at positive potentials (Fig. $3 C$ ). The ratio of the time

response was $1.7 \pm 1.0(n=18)$ (Fig. $2 A 3)$. As shown below, both the glutamatergic current and the nicotinic current could be separated pharmacologically into two components.

The separation of the four components of the synaptic current usually required the successive application of the four selective antagonists NBQX, D-APV, MLA, and DH $\beta E$. The order of application of these antagonists was varied depending on the component to be studied. Because the relative contribution of the four components to the total response was quite variable from one experiment to another, the effect of a given antagonist could not always be detected by measuring only the amplitude of the response. Supplemental Figure 1 (available at www.jneurosci.org as supplemental material) illustrates the case of two experiments where the four antagonists were applied in the same sequence: NBQX and NMDA, then MLA, then DH $\beta E$. In the first case the glutamatergic components were small, and their suppression was not detectable as a change of the peak response. However the suppression of the slowly decaying NMDAR component was detected by the shortening of the decay. In the second experiment the glutamatergic components were large and the MLA-sensitive component small. The suppression of the glutamatergic components produced a marked change in the peak, as well as in the decay time. MLA produced only a slight change in peak amplitude, no change in the decay time but a marked change in the rise time of the response. constant measured at $+45 \mathrm{mV}$ over that measured at $-45 \mathrm{mV}$ was $2.8 \pm 0.6(n=5)$. The $I-V$ relation of the peak NMDARmediated current showed the well known negative conductance due to $\mathrm{Mg}^{2+}$ block. It was fitted using an equation of the type used by Woodhull (1973) with values for $K(0)$ and $\delta$ (see Materials and Methods) of $10 \mathrm{~mm}$ and 0.82 . (Fig. 3D). This voltage dependence of the peak current resembles that found in both native and recombinant NMDARs that incorporate the NR2A and NR2B subunits. The voltage dependence of the decay of the NMDAR-mediated current, on the other hand, resembles that first reported in dentate granule cells (Konnerth et al., 1990), and since seen in many neurons. This voltage dependence has not been observed in recombinant receptors. It may be due to the voltage sensitivity of glutamate transporters clearing glutamate from the synaptic cleft (Diamond, 2001). It is likely to play a functional role by prolonging the NMDAR-mediated response once it has been activated.

The ratio of the peaks of the AMPAR- and NMDAR-mediated components measured at $-45 \mathrm{mV}$ was $0.7 \pm 0.6(n=17)$ (Fig. 2B3).

\section{The two components of the RC cholinergic current}

MLA and $\mathrm{DH} \beta \mathrm{E}$, in a limited range of concentrations, can separate a group of nAChRs often called "homomeric receptors" (for which the prototype is the homomeric $\alpha_{7}$ receptor, but which 
includes $\alpha_{9}-\alpha_{10}$ heteromers) from a large group of "heteromeric receptors" (for which the prototype is $\alpha_{4} \beta_{2}$ ). MLA at 10 $\mathrm{nM}$ is a selective antagonist of the homomeric receptors and has very little effect on the heteromeric ones. Conversely $\mathrm{DH} \beta \mathrm{E}$ up to $3 \mu \mathrm{M}$ acts selectively on the heteromeric receptors, although at higher concentrations it affects the homomeric ones (Chavez-Noriega et al., 1997).

When MLA (10 nM) was applied after the nicotinic current had been isolated by the prior addition of D-APV and NBQX, it eliminated selectively a fast-rising, fastdecaying component (Fig. 2C). The residual "slow" component was reduced by $>90 \%$ by $\mathrm{DH} \beta \mathrm{E}$ at $3 \mu \mathrm{M}$. (Fig. $2 \mathrm{C1}, \mathrm{C} 2$ ). Conversely, if $\mathrm{DH} \beta \mathrm{E}$ at $3 \mu \mathrm{M}$ was applied before MLA, it eliminated selectively a slow component of the total nicotinic current (data not shown) and left the fast current illustrated in Figure $4 \mathrm{~A}$. The ratio of the peaks of the MLA-sensitive component over that of the $\mathrm{DH} \beta \mathrm{E}$-sensitive component was $1.21 \pm 0.7(n=5)$ (Fig. $2 C 3)$.

For the MLA-sensitive component, at $-45 \mathrm{mV}$, the value of $\tau_{\mathrm{p}}$, was $0.5 \pm 0.2 \mathrm{~ms}$ $(n=10)$ and the value of $\tau_{\mathrm{d}}$ was $3.6 \pm 2.2$ $\mathrm{ms}(n=10)$. For the $\mathrm{DH} \beta \mathrm{E}$-sensitive component the mean value of $\tau_{\mathrm{p}}$ was $1.8 \pm 0.4$ ms $(n=10)$ and the mean value of $\tau_{\mathrm{d}}$ was $20.2 \pm 3.4 \mathrm{~ms}(n=10)$ (Fig. 2C3).

Both of the nicotinic responses showed inward rectification (Fig. $4 B, D$ ). The $I-V$ curves could be fitted with a Woodhull equation and gave similar values for $K(0) /\left[\mathrm{Mg}^{2+}\right]_{\mathrm{i}}$ and $\delta$ (measured from the inside, see Materials and Methods): 0.19 and 0.86 for the MLA-sensitive component and 0.22 and 0.96 for the $\mathrm{DH} \beta \mathrm{E}$-sensitive component. It should be noted that in these experiments spermine had not been added to the internal solution, and therefore the main intracellular blocker was likely to be $\mathrm{Mg}^{2+}$.

In an attempt to identify the subtypes of nAChRs involved in the two nicotinic responses, $\mathrm{DH} \beta \mathrm{E}$ was tested on the response persisting after D-APV, NBQX, and MLA. It reduced the response to $51.3 \pm 6.8 \%(n=4)$ of the control value at $0.1 \mu \mathrm{M}$, to $26.2 \pm$ $5.6 \%(n=7)$ at $0.3 \mu \mathrm{M}$, to $12.9 \pm 1.4 \%(n=7)$ at $1 \mu \mathrm{M}$, to $7.5 \pm$ $2.5 \%(n=4)$ at $3 \mu \mathrm{M}$, and to $3.4 \pm 1.4 \%(n=6)$ at $10 \mu \mathrm{M}$. This corresponds to an $\mathrm{IC}_{50}$ of $\sim 0.1 \mu \mathrm{M}$, which points to a subgroup of heteromeric nAChRs characterized as " $\alpha_{4} \beta_{2}$ with a low affinity for ACh" (see Discussion). When (in the absence of MLA) DH $\beta \mathrm{E}$ was applied at $10 \mu \mathrm{M}$ after having been applied at $3 \mu \mathrm{M}$, it produced a significant but incomplete block of the "fast" residual response. This is consistent with previous reports (ChavezNoriega et al., 1997) indicating that, at $10 \mu \mathrm{M}, \mathrm{DH} \beta \mathrm{E}$ starts losing its selectivity against the various subtypes of nAChRs.

$\mathrm{MEC}$, at $50 \mu \mathrm{M}$, blocked most of the nicotinic response (Fig. $2 B$ ) as reported by Nishimaru et al. (2005). This is in agreement with the observation that MEC does not discriminate between $\alpha_{4} \beta_{2}$-like receptors and $\alpha_{7}$ receptors (Chavez-Noriega et al., 1997).

Strychnine (Matsubayashi et al., 1998; Bradaïa and Trouslard, 2002) and bicuculline (Demuro et al., 2001) have been reported to block the MLA-sensitive $\alpha_{7}$ receptors. Indeed, the responses
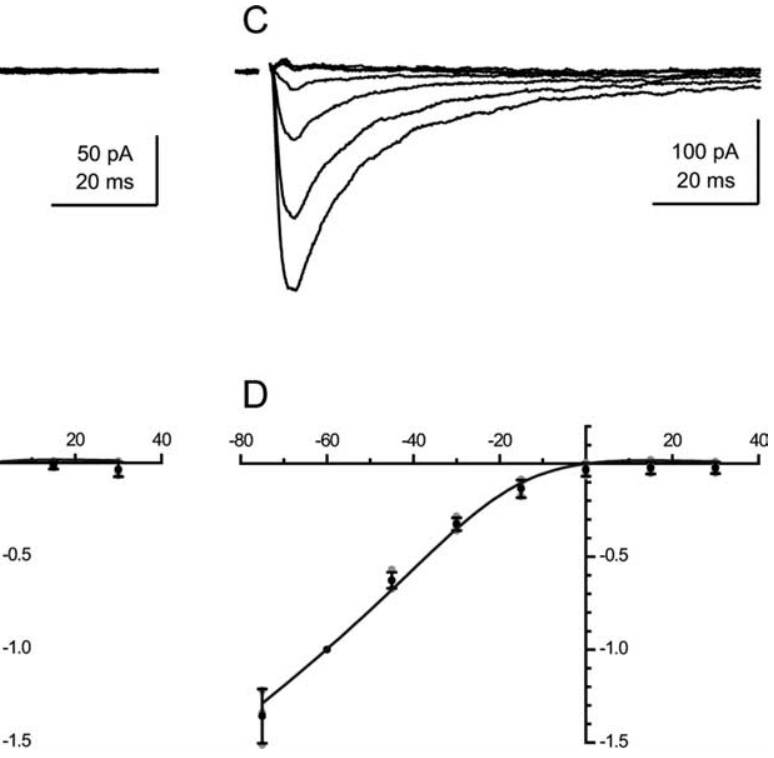

Figure 4. Voltage dependence of the two nicotinic components of the RC synaptic current. The total nicotinic current was first

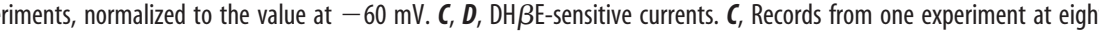
normalized to the value at $-60 \mathrm{mV}$. The continuous lines represent a fit of the $I-V$ relations using a Woodhull model (1973). The values of the parameters are given in Results.

observed after D-APV (50 $\mu \mathrm{M}), \operatorname{NBQX}(2 \mu \mathrm{M})$, and DH $\beta \mathrm{E}(3 \mu \mathrm{M})$ were reduced by strychnine at $1 \mu \mathrm{M}$ (by $57 \pm 18 \%, n=4)$ and by bicuculline at $5 \mu \mathrm{M}$ (by $48 \pm 8 \%, n=3$ ).

\section{The response of MNs to a VR stimulation}

We analyzed how the antagonists of the four receptor types modified the train of IPSCs recorded in the MNs after a VR stimulation. As mentioned before, this train shows two early peaks P1 and $\mathrm{P} 2$ and a late $\mathrm{P} 3$ component (Schneider and Fyffe, 1992). The amplitude of $\mathrm{P} 3$ was quite variable: it could reach hundreds of $\mathrm{pA}$ at $-45 \mathrm{mV}$ but could also be small or absent. A survey of the experiments in which P3 was large suggested a correlation with a depolarized resting potential of RCs. This is consistent with the idea that the late discharge of the RC requires a priming depolarization (see below).

D-APV $(50 \mu \mathrm{M})$ reduced P1, P2, and P3 (Fig. 5A). The P2 peak was reduced to $64 \pm 16 \%$ of its initial value, whereas the P3 response was reduced to $25 \pm 15 \%(n=10)$. The residual component measured at 50-100 ms was essentially due to the tail of the P2 synaptic current.

$\mathrm{DH} \beta \mathrm{E}(3-10 \mu \mathrm{M})$ also reduced $\mathrm{P} 1$ and $\mathrm{P} 2$ and even more severely P3 (Fig. 5B). P2 and P3 were reduced to $47 \pm 3 \%$ and to $12 \pm 7 \%$ of their initial values $(n=3)$. A concentration of $1 \mu \mathrm{M}$ was often sufficient to produce a complete elimination of the P3 component. A reduction of $\mathrm{P} 3$ was already detectable with a concentration of $\mathrm{DH} \beta \mathrm{E}$ of $0.1 \mu \mathrm{M}$, which blocks $50 \%$ of the $\mathrm{DH} \beta \mathrm{E}$ sensitive current in the RC.

NBQX $(2 \mu \mathrm{M})$ and MLA (10 nM) both reduced P1, P2, and P3, but, in contrast to the cases of D-APV and $\mathrm{DH} \beta \mathrm{E}$, the three components were on average reduced in similar proportions (NBQX: P2 $59 \pm 7 \%$ and P3 $47 \pm 20 \%, n=10$; MLA: $85 \pm 35 \%$ and $69 \pm$ $34 \%, n=6$ ) (Fig. 5C,D). 

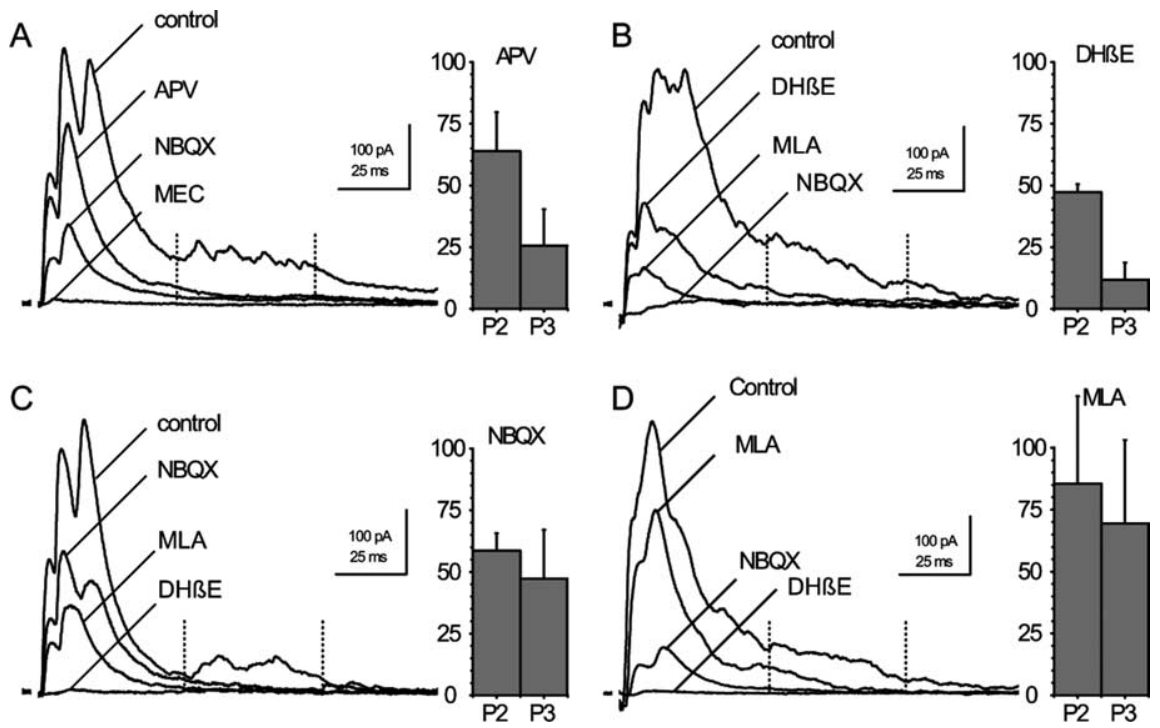

Figure 5. MN responses to VR stimulation after successive blockade of the four receptors. The four sets of records illustrate four experiments in which three antagonists were applied in succession. The first antagonist applied was different in each experiment and the bar graphs near each set of records represent the mean effect of that antagonist on P2 and P3 (D-APV in $A, D H \beta E$ in $B, N B Q X$ in $\boldsymbol{C}, \mathrm{MLA}$ in $\boldsymbol{D})$. $\boldsymbol{A}$, D-APV $(50 \mu \mathrm{m})$ was followed by NBQX $(2 \mu \mathrm{M})$ and MEC $(50 \mu \mathrm{m}) . n=10 . \boldsymbol{B}$, DH $\beta \mathrm{E}(3 \mu \mathrm{M})$ was followed by MLA $(10 \mathrm{~nm})$ and NBQX $(2 \mu \mathrm{M}) . n=3$. C, NBQX $(2 \mu \mathrm{M})$ followed by MLA $(10 \mathrm{~nm})$ and DH $\beta E(10 \mu \mathrm{M}) . n=10 . D, M L A(10 \mathrm{~nm})$ followed by NBQX $(2 \mu \mathrm{m})$ and $\mathrm{DH} \beta \mathrm{E}(10 \mu \mathrm{m}) . n=6$. Bar graphs, For $\mathrm{P} 2$ the reduction was measured as the ratio of the $\mathrm{P} 2$ peaks. For $\mathrm{P} 3$ it was measured as the ratio of the mean currents between 50 and $100 \mathrm{~ms}$ after the beginning of the response (between the dotted lines). Values are in the text. Holding potential $-45 \mathrm{mV}(\boldsymbol{A}, \boldsymbol{B})$ and $-15 \mathrm{mV}(\boldsymbol{C}, \boldsymbol{D})$. All records are averages of 10 consecutive traces acquired at 10 s intervals.

The fractional block produced by a given compound appeared proportionally larger when it was applied as a second or third antagonist. This can be interpreted by assuming that the early doublet responsible for P1 and P2 is all-or-none and that the total current contributed by the four receptors is larger than the current needed to bring the membrane potential to threshold. With the application of a single antagonist the contribution of the corresponding receptor to the activation of the $\mathrm{RC}$ is masked by a "safety factor" such that the elimination of one component does not impede the access to the spike threshold.

The pharmacological analysis of the $\mathrm{MN}$ response indicates that the early peaks (P1-P2) are affected by antagonists of each of the four receptors. The late (P3) component of the RC discharge is strongly reduced either by blocking the NMDARs or by blocking the $\mathrm{DH} \beta \mathrm{E}$-sensitive $\mathrm{nAChRs}$. It is less affected by NBQX or MLA. The reason for, which $\mathrm{DH} \beta \mathrm{E}$ is more effective on $\mathrm{P} 3$ than MLA or NBQX is likely to be that the $\mathrm{DH} \beta \mathrm{E}$-sensitive response has a slower decay than either the MLA-sensitive component or the AMPAR-mediated component (20 ms vs 3.6 or $6 \mathrm{~ms}$ ) for a similar peak value, which implies that it carries $\sim 4$ times more charge.

\section{The response of the $\mathrm{RC}$ in current clamp}

To record from the RCs in current clamp, we used a $\mathrm{K}^{+}$-based internal solution. Figure $6 \mathrm{~A}$ illustrates the effects of D-APV on the $\mathrm{RC}$ discharge recorded near resting potential. In control conditions, the initial doublet of action potentials ( $1-\mathrm{p} 2$ ) was followed by a single action potentials with a more variable latency (p3). To quantify $\mathrm{p} 1$ and $\mathrm{p} 2$ we counted the fraction of the cases in which the first and the second action potentials were observed. To quantify p 3 in a way similar to that used to quantify the late response of MNs (P3) in Figure 5, we calculated the average number of action potentials in the window from 50 to $100 \mathrm{~ms}$ after the stimulation. In the case of the response illustrated in Figure $6 A, \mathrm{p} 1$ and $\mathrm{p} 2$ were equal to 1 , whereas $\mathrm{p} 3$ was equal to 0.8 . After addition of $\mathrm{D}-\mathrm{APV}, \mathrm{p} 1$ remained equal to 1 , but $\mathrm{p} 2$ and $\mathrm{p} 3$ fell to 0 . The later addition of MLA (10 nM), DH $\beta \mathrm{E}(10 \mu \mathrm{M})$, and NBQX $(2 \mu \mathrm{M})$ eliminated p1. This experiment was repeated in 10 cells. In control conditions the mean values were $\mathrm{p} 1=$ $1 \pm 0, \mathrm{p} 2=0.86 \pm 0.32$, and $\mathrm{p} 3=0.70 \pm$ 0.25 . After addition of D-APV the values fell to $\mathrm{p} 1=0.91 \pm 0.17, \mathrm{p} 2=0.25 \pm 0.41$, and $\mathrm{p} 3=0.07 \pm 0.16$. This is qualitatively in agreement with the records obtained in the MNs (Fig. 5A). The main discrepancy appears to be that D-APV has a smaller effect on $\mathrm{p} 1$ than on $\mathrm{P} 1$. This could reflect the fact that we selected RC responses with high values of $\mathrm{p} 1$ in control conditions, as well as to the fact that the reduction of $\mathrm{p} 2$ is often associated with a shift of latency of p1. At the level of the MN recurrent IPSCs, this shift of latency could contribute to an increase of the P2 peak (and a further reduction of $\mathrm{P} 1$ ).

Figure $6 B$ illustrates the differential effects of the holding potential on the early and late components of the $\mathrm{RC}$ response. At resting potential $(-64 \mathrm{mV})$ the response had the same structure as the response of Figure $6 A$, i.e., a doublet followed by a late "p3" action potential. Depolarization of the cell to $-58 \mathrm{mV}$ suppressed the doublet and increased the duration of the late discharge. In contrast hyperpolarizing the cell to $-75 \mathrm{mV}$ essentially suppressed the late discharge while the initial doublet persisted. The sensitivity of the late discharge to membrane potential is expected if this component is controlled by a NMDAR-dependent current. On the other hand, the voltage sensitivity of the doublet suggested the contribution of voltage-dependent intrinsic conductances. This possibility was examined by analyzing the response of the $\mathrm{RC}$ to a direct depolarization.

Figure $6 C$ illustrates the responses of a $\mathrm{RC}$ to a depolarizing current step applied at two holding potentials. When the holding potential was $-75 \mathrm{mV}$, a depolarizing pulse induced a regular discharge, the frequency of, which depended on the intensity of the depolarizing current. In contrast, when the holding potential was brought to $-82 \mathrm{mV}$, the depolarizing pulse triggered a doublet followed by a late train, i.e., produced a response similar to the response to a VR stimulation. Increasing the depolarizing current pulse did not modify the initial doublet, but increased the frequency of the spikes in the late discharge. The initial doublet thus depends on the value of the holding potential, whereas the frequency of the late train appears controlled only by the value of the steady current.

The dependence of the doublet on the holding potential suggests the presence of voltage-dependent conductances inactivated by a steady depolarization, such as a T-type $\mathrm{Ca}^{2+}$ current, or a slow $\mathrm{Na}^{+}$current (see Bean, 2007). The production of the doublet itself must also involve both fast $\mathrm{K}^{+}$currents (allowing a rapid repolarization after the first spike) and slower $\mathrm{K}^{+}$currents (to account for the interval between the doublet and the later spikes). We found that both apamin $(0.2 \mu \mathrm{M})$ and 4 -aminopyridine (4-AP) $(25 \mu \mathrm{M})$ transformed the doublet into a longer 
discharge. 4-AP also enlarged the late spikes (data not shown). These observations suggest that the repolarization ending the doublet involves SK channels (sensitive to apamin) and/or $\mathrm{K}^{+}$currents sensitive to low concentrations of 4-AP (see Bean, 2007).

A complete interpretation of the $\mathrm{RC}$ discharge may require additional elements to account for the fact that, although D-APV reduces drastically p3 (Fig. 6A) and P3 (Fig. 5A), the blockade of the late action potentials is not always complete.

Finally, the contribution of the four receptors to the pattern of spiking may be influenced by the fact that the receptors have different $\mathrm{Ca}^{2+}$ permeabilities. AMPARs with linear $I-V$ relations have a low $\mathrm{Ca}^{2+}$ permeability, whereas NMDARs and MLA-sensitive nAChRs have a very high $\mathrm{Ca}^{2+}$ permeability. A possible effect of $\mathrm{Ca}^{2+}$ entry through both receptors is the activation of $\mathrm{K}^{+}$currents. We looked for such currents in the case of the MLAsensitive receptors by recording RC synaptic currents using a $\mathrm{K}^{+}$-based solution containing a low amount of $\mathrm{Ca}^{2+}$ buffer (1 $\mathrm{mM}$ or $0.1 \mathrm{~mm}$ EGTA) and QX-314 (5 $\mathrm{mM})$, and isolating the MLA-sensitive component with D-APV, NBQX, and $\mathrm{DH} \beta \mathrm{E}(3 \mu \mathrm{M})$. The response recorded in these conditions was similar to that recorded with a $\mathrm{Cs}^{+}$-based solution, and no $\mathrm{K}^{+}$current could be detected (data not shown). We did not analyze whether the NMDAR activation could activate $\mathrm{K}^{+}$currents but such currents could account for the "pause" of the RC discharge that has been described by Curtis and Ryall (1966), and the depression of the response to a second VR stimulation that was reported by Renshaw (1946) and Eccles et al. (1954). However $\mathrm{Ca}^{2+}$ fluxes could have other effects than activating $\mathrm{K}^{+}$currents and it is worth mentioning that, in other synapses, $\mathrm{Ca}^{2+}$ entry through MLA-sensitive receptors has been shown to inhibit neighboring GABA and glycine receptors (Wanaverbecq et al., 2007; Zhang and Berg, 2007).

\section{Discussion}

Our results support the hypothesis that the long duration of the RC action potential train results mostly from the activation of the NMDARs after a priming depolarization has relieved the $\mathrm{Mg}^{2+}$ block. This priming depolarization is provided mostly by the $\mathrm{DH} \beta \mathrm{E}$-sensitive component of the nicotinic response. The decisive role of this component, already revealed by the pioneer work of Eccles et al. (1954), is likely due to the fact that it carries more charge than the two fast components.

The time constants of decay of the four synaptic currents are likely to be over-estimated because the inputs are not perfectly synchronous and the measures were made at room temperature. However, these factors should not alter the relative order of the
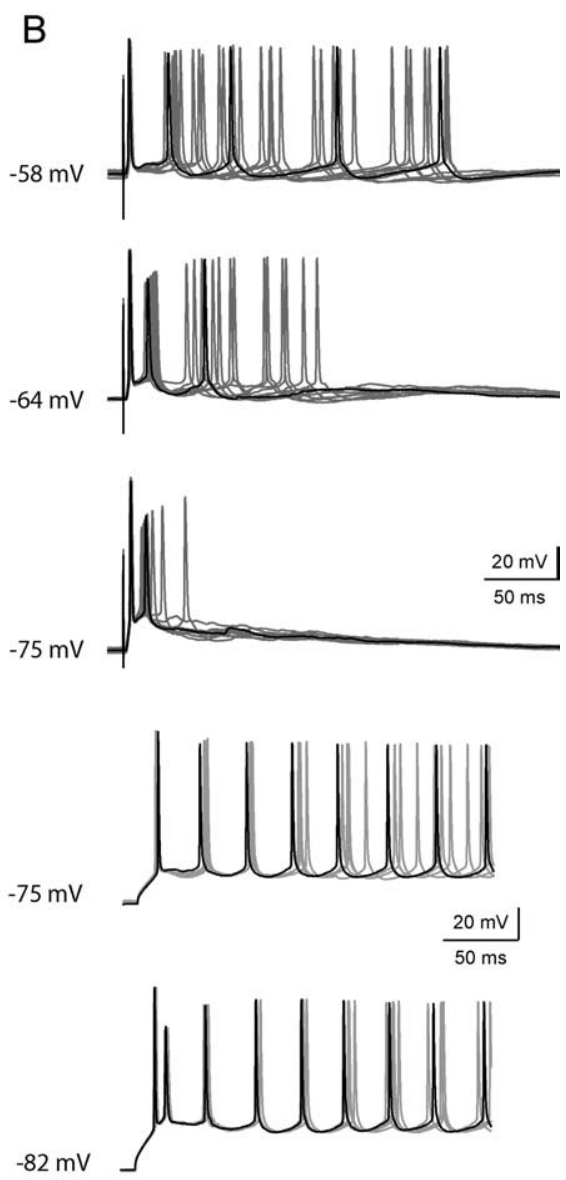

Figure 6. Responses of the RCs in current clamp. Records were obtained in the whole-cell mode (current clamp) with a $\mathrm{K}^{+}$-based internal solution. $\boldsymbol{A}, \boldsymbol{B}$, Responses to a VR stimulation. $\boldsymbol{C}$, Responses to the injection of a step of depolarizing current. $\boldsymbol{A}$, Effects of D-APV on the RC response to a VR stimulation. Top to bottom: the control response showed an initial doublet and a $\mathrm{p} 3$ response consisting of a single action potential (in one sweep, a second late spike occurs after the time window of 50-100 ms and is therefore not counted as " $\mathrm{p3}$ "). Addition of D-APV eliminated both $\mathrm{p} 2$ and $\mathrm{p} 3$. Addition of MLA (10 nm), DH $\beta E(10 \mu \mathrm{m})$, and NBQX response recorded at the resting potential (-64 $\mathrm{mV}$, middle trace) consisted of an initial doublet of action potentials (p1-p2) followed by a late brief discharge (p3). When the cell was depolarized to $-58 \mathrm{mV}$ (top trace) the doublet disappeared whereas the eft intact the initial doublet of action potentials. $C$, Phasic and tonic components of the response to a current step. When the pulse elicited both a phasic response (the first doublet of spike) followed by a tonic response (the late regular discharge). Increasing the amplitude of the current pulse from $120 \mathrm{pA}$ (left) to $160 \mathrm{pA}$ (right) only accelerated the late firing.

time constants. We propose that the "staggering" of the time constants has a physiological function, allowing the discharge of the $\mathrm{RC}$ to cover a wide range of frequencies. The spread of the time constants may be necessary for a full priming of the NMDAR response whose activation is so slow that it is not complete by the time the AMPAR-mediated currents and the MLAsensitive currents have returned to zero.

\section{The subunit composition of the nicotinic receptors}

The MLA-sensitive component has the characteristics of a response mediated by a homomeric $\alpha_{7}$ receptor: it is very sensitive to MLA (Alkondon et al., 1992; Buisson et al., 1996; ChavezNoriega et al., 1997). Its rapid decay may reflect fast dissociation from the $\alpha_{7}$ receptor $\left(\mathrm{EC}_{50}\right.$ values $>100 \mu \mathrm{M}$ ) (Couturier et al., 1990; Alkondon et al., 1992; Chavez-Noriega et al., 1997) or, 
more probably, fast desensitization (Bouzat et al., 2008). However, MLA also blocks $\alpha_{9} / \alpha_{10}$ receptors, which may be present in the spinal cord (Haberberger et al., 2004). The fact that the MLA-sensitive response was not identified in previous work on RCs may result in part from the fact that it is sensitive to strychnine and to bicuculline, which had been added in control conditions in many previous studies (e.g., Dourado and Sargent 2002).

The $\mathrm{DH} \beta \mathrm{E}$-sensitive component could involve $\alpha 4$ - or $\alpha 2$ containing heteromeric receptors. Dourado and Sargent (2002) found immunochemical evidence for $\alpha 4$ and $\beta 2$ subunits in RCs, but Ishii et al. (2005) recently reported the presence of $\alpha 2$ subunits in small neurons of the ventral horn. The sensitivity to $\mathrm{DH} \beta \mathrm{E}$ that we have observed $\left(\mathrm{IC}_{50}\right.$ of $\left.0.1 \mu \mathrm{M}\right)$ is close to that reported for the subgroup of $\alpha_{4} \beta_{2}$ receptors with a low sensitivity to $\mathrm{DH} \beta \mathrm{E}\left(K_{\mathrm{b}}=\sim 0.1 \mu \mathrm{M}\right)$ (Moroni et al., 2006; Chavez-Noriega et al., 1997) and quite different from that reported for $\alpha 2 \beta 2$ receptors $\left(K_{\mathrm{b}}=85 \mu \mathrm{M}\right)$ (Chavez-Noriega et al., 1997) or for the subgroup of $\alpha_{4} \beta_{2}$ receptors with a high sensitivity to $\mathrm{DH} \beta \mathrm{E}\left(K_{\mathrm{b}}\right.$ $=\sim 10 \mathrm{nM}$ ) (Moroni et al., 2006). This strongly suggests that the $\mathrm{RC}$ heteromeric receptors belong to the subgroup of $\alpha_{4} \beta_{2}$ receptors with a low sensitivity to $\mathrm{DH} \beta \mathrm{E}$. The $\mathrm{EC}_{50}$ for ACh of these receptors is in the tens of $\mu \mathrm{M}$ (Chavez-Noriega et al., 1997; Covernton and Connolly, 2000; Moroni et al., 2006). The $\alpha_{4} \beta_{2}$ receptors with a high sensitivity to $\mathrm{DH} \beta \mathrm{E}$, which have a low $\mathrm{EC}_{50}$ for ACh (0.3-3 $\mu \mathrm{M}$ ) (Buisson et al., 1996; Zwart and Vijverberg, 1998; Covernton and Connolly 2000; Moroni et al., 2006) and thus could be expected to mediate slow responses, do not appear responsible for the long duration of the $\mathrm{RC}$ discharge.

\section{The MN-RC synapse as a model for a central nicotinic synapse}

Synaptic currents involving a fast MLA-sensitive receptor and a slow $\mathrm{DH} \beta \mathrm{E}$-sensitive receptor have been previously documented in peripheral ganglionic synapses, in particular in the chick ciliary ganglion (Zhang et al., 1996), and fast and slow postsynaptic nAChRs have been found to coexist in many central neurons, like the dopaminergic neurons of the substantia nigra, or the hippocampal interneurons of CA1 (Matsubayashi et al., 2004; Dani and Bertrand, 2007). Although most of the postsynaptic currents dependent on nAChRs in the vertebrate CNS have been attributed to $\alpha_{7}$ receptors (Alkondon et al., 1998; Frazier et al., 1998; Hefft et al., 1999; Bradaïa and Trouslard, 2002; Hatton and Yang, 2002), their pharmacological characterization was often only partial, which leaves open the possibility of the presence of an additional non- $\alpha_{7}$ component.

\section{Simultaneous release of $\mathrm{ACh}$ and glutamate}

The hypothesis that $\mathrm{nAChRs}$ are used to prime the NMDARs gives a functional sense to the simultaneous activation of ACh and glutamate receptors at the $\mathrm{MN}-\mathrm{RC}$ synapse. Mentis et al. (2005) hesitated to accept the idea that glutamate and ACh are coreleased by the MN terminals because, contrary to Herzog et al. (2004) and Nishimaru et al. (2005), they could not identify vesicular glutamate transporters in MN axons. Although we have not brought new evidence to this controversy, our data appear consistent with the hypothesis that glutamate and ACh be coreleased by the motor axon collaterals.

The corelease of ACh and glutamate was first suggested for the innervation of the Torpedo electric organ (Israël et al., 1993). Colocalization of $\mathrm{ACh}$ and glutamate has been reported in the three major cholinergic systems of the brain, the pedunculopontine nucleus (Lavoie and Parent 1994), the basal forebrain neu- rons (Nickerson Poulin et al., 2006), and the cholinergic interneurons of the striatum (Fremeau et al., 2004). A direct demonstration of corelease has however been rarely obtained. Li et al. (2004) provided it in frog tadpoles for identified spinal interneurons. For the MN-RC synapse, the only evidence for a corelease from the same $\mathrm{MN}$ is the paired recording between a $\mathrm{MN}$ and a RC obtained by Nishimaru et al. (2005). Finally, individual "cholinergic" neurons of the basal forebrain have been shown, at least in culture, to release both glutamate and ACh (Allen et al., 2006; Huh et al., 2008). In none of the above experiments was a postsynaptic $\alpha_{7}$ component identified, but Li et al. (2004) recorded in the presence of strychnine, bicuculline, and $\alpha$-bungarotoxin, while Nishimaru et al. (2005) and Huh et al. (2008) used broad spectrum nicotinic antagonists. One may wonder whether the synapses of mixed cholinergic-glutamatergic neurons do not often resemble the four-receptor $\mathrm{MN}-\mathrm{RC}$ synapse.

\section{From young mice to adult animals}

Our results were obtained at room temperature and on young mice (P5-P10), and one wonders whether they can be extended to physiological temperature and adult animals. The NMDARmediated component is likely to be accelerated at physiological temperature. This acceleration has been well documented in the case of recombinant receptors expressing NR2B (Cais et al., 2008), and more recently evaluated by M. Casado (personal communication) for recombinant receptors expressing NR2A, which have a decay time comparable to that of the responses that we have studied. In both cases, the time constant of decay at $-45 \mathrm{mV}$ would be between 20 and $25 \mathrm{~ms}$ at $37^{\circ} \mathrm{C}$, thus compatible with the average duration of the responses observed in the adult cat (30-50 ms) (Renshaw, 1946; Eccles et al., 1954). Against the role of NMDARs in adults is the fact that, when Davies and Watkins (1979) analyzed in adult rats the effect of $\mathrm{D}$ - $\alpha$-amino-adipate, an NMDAR antagonist, they saw no change in the RC discharge. However, the discharges analyzed lasted only $\sim 10 \mathrm{~ms}$, and may have had a reduced NMDAR-mediated component as seen when the resting potential of the RCs is very negative.

RCs in neonatal rats or mice do not show the high-frequency discharge that is so striking in the records from adult cats (Renshaw, 1946; Eccles et al., 1954, 1961). An explanation for this difference may be provided by the report that, in mice, both calbindin and the $\mathrm{K}^{+}$channel subunit Kv1.3b are only expressed strongly after P10 (Song et al., 2006). Channels containing Kv1.3b subunits could help produce a fast repolarization after each action potential, whereas calbindin might limit the AHP and allow high-frequency firing. Recording from older animals thus appears as a major objective for further studies, but it poses technical problems that have yet to be solved.

\section{Responses of the RC in physiological conditions}

In physiological conditions, the RCs probably rarely receive a synchronous and massive excitation from the MNs. During fictive locomotion, the RCs alternate between a hyperpolarized silent state and a depolarized state during which they fire at relatively low frequency (McCrea et al., 1980). Our observations on the voltage sensitivity of the $\mathrm{RC}$ responses suggest that during the hyperpolarized state an input from the MNs may trigger only a spike doublet, whereas the same input, arriving during the depolarized state, may not elicit a doublet but accelerate the tonic discharge through a NMDAR-dependent depolarization. The ratio of the early and late components of the RC response may thus depend on the membrane potential of the RC and the phasic and 
tonic components may be used separately during the two functional states of the network.

\section{References}

Alkondon M, Pereira EF, Wonnacott S, Albuquerque EX (1992) Blockade of nicotinic currents in hippocampal neurons defines methyllycaconitine as a potent and specific receptor antagonist. Mol Pharmacol 41:802-808.

Alkondon M, Pereira EF, Albuquerque EX (1998) Alpha-bungarotoxinand methyllycaconitine-sensitive nicotinic receptors mediate fast synaptic transmission in interneurons of rat hippocampal slices. Brain Res 810:257-263.

Allen TG, Abogadie FC, Brown DA (2006) Simultaneous release of glutamate and acetylcholine from single magnocellular "cholinergic" basal forebrain neurons. J Neurosci 26:1588-1595.

Alvarez FJ, Fyffe REW (2007) The continuing case for the Renshaw cell. J Physiol 584:31-45.

Bean BP (2007) The action potential in mammalian central neurons. Nat Rev Neurosci 8:451-465.

Bouzat C, Bartos M, Corradi J, Sine SM (2008) The interface between extracellular and transmembrane domains of homomeric Cys-loop receptors governs open-channel lifetime and rate of desensitization. J Neurosci 28:7808-7819.

Bradaïa A, Trouslard J (2002) Fast synaptic transmission mediated by alpha-bungarotoxin-sensitive nicotinic acetylcholine receptors in lamina $\mathrm{X}$ neurones of neonatal rat spinal cord. J Physiol 544:727-739.

Brunel N, Hakim V, Isope P, Nadal JP, Barbour B (2004) Optimal information storage and the distribution of synaptic weights: perceptron versus Purkinje cell. Neuron 43:745-757.

Buisson B, Gopalakrishnan M, Arneric SP, Sullivan JP, Bertrand D (1996) Human $\alpha_{4} \beta_{2}$ neuronal nicotinic acetylcholine receptor in HEK 293 cells: a patch-clamp study. J Neurosci 16:7880-7891.

Cais O, Sedlacek M, Horak M, Dittert I, Vyklicky L Jr (2008) Temperature dependence of NR1/NR2B NMDA receptor channels. Neuroscience 151:428-438.

Chavez-Noriega LE, Crona JH, Washburn MS, Urrutia A, Elliott KJ, Johnson EC (1997) Pharmacological characterization of recombinant human neuronal nicotinic acetylcholine receptors $h$ alpha 2 beta 2 , $\mathrm{h}$ alpha 2 beta 4 , h alpha 3 beta 2 , h alpha 3 beta 4 , h alpha 4 beta 2, h alpha 4 beta 4 and $\mathrm{h}$ alpha 7 expressed in Xenopus oocytes. J Pharmacol Exp Ther 280:346-356.

Couturier S, Bertrand D, Matter JM, Hernandez MC, Bertrand S, Millar N, Valera S, Barkas T, Ballivet M (1990) A neuronal nicotinic acetylcholine receptor subunit (alpha 7) is developmentally regulated and forms a homo-oligomeric channel blocked by alpha-BTX. Neuron 5:847-856.

Covernton PJ, Connolly JG (2000) Multiple components in the agonist concentration-response relationships of neuronal nicotinic acetylcholine receptors. J Neurosci Methods 96:63-70.

Curtis DR, Ryall RW (1966) The synaptic excitation of Renshaw cells. Exp Brain Res 2:81-96.

Dani JA, Bertrand D (2007) Nicotinic acetylcholine receptors and nicotinic cholinergic mechanisms of the central nervous system. Annu Rev Pharmacol Toxicol 47:699-729.

Davies J, Watkins JC (1979) Selective antagonism of amino acid-induced and synaptic excitation in the cat spinal cord. J Physiol 297:621-635.

Demuro A, Palma E, Eusebi F, Miledi R (2001) Inhibition of nicotinic acetylcholine receptors by bicuculline. Neuropharmacology 41:854-861.

Diamond JS (2001) Neuronal glutamate transporters limit activation of NMDA receptors by neurotransmitter spillover on CA1 pyramidal cells. J Neurosci 21:8328-8338.

Dourado M, Sargent PB (2002) Properties of nicotinic receptors underlying Renshaw cell excitation by alpha-motor neurons in neonatal rat spinal cord. J Neurophysiol 87:3117-3125.

Dugué GP, Dumoulin A, Triller A, Dieudonné S (2005) Target-dependent use of coreleased inhibitory transmitters at central synapses. J Neurosci 25:6490-6498.

Eccles JC, Jaeger JC (1958) The relationship between the mode of operation and the dimensions of the junctional regions at synapses and motor endorgans. Proc R Soc Lond B Biol Sci 148:38-56.

Eccles JC, Fatt P, Koketsu K (1954) Cholinergic and inhibitory synapses in a pathway from motor-axon collaterals to motoneurones. J Physiol 126:524-562.
Eccles JC, Eccles RM, Iggo A, Lundberg A (1961) Electrophysiological investigations on Renshaw cells. J Physiol 159:461-478.

Frazier CJ, Buhler AV, Weiner JL, Dunwiddie TV (1998) Synaptic potentials mediated via $\alpha$-bungarotoxin-sensitive nicotinic acetylcholine receptors in rat hippocampal interneurons. J Neurosci 18:8228-8235.

Fremeau RT Jr, Voglmaier S, Seal RP, Edwards RH (2004) VGLUTs define subsets of excitatory neurons and suggest novel roles for glutamate. Trends Neurosci 27:98-103.

Haberberger RV, Bernardini N, Kress M, Hartmann P, Lips KS, Kummer W (2004) Nicotinic acetylcholine receptor subtypes in nociceptive dorsal root ganglion neurons of the adult rat. Auton Neurosci 113:32-42.

Hatton GI, Yang QZ (2002) Synaptic potentials mediated by $\alpha_{7}$ nicotinic acetylcholine receptors in supraoptic nucleus. J Neurosci 22:29-37.

Hefft S, Hulo S, Bertrand D, Muller D (1999) Synaptic transmission at nicotinic acetylcholine receptors in rat hippocampal organotypic cultures and slices. J Physiol 515:769-776.

Herzog E, Landry M, Buhler E, Bouali-Benazzouz R, Legay C, Henderson CE, Nagy F, Dreyfus P, Giros B, El Mestikawy S (2004) Expression of vesicular glutamate transporters, VGLUT1 and VGLUT2, in cholinergic spinal motoneurons. Eur J Neurosci 20:1752-1760.

Hollmann M, Heinemann S (1994) Cloned glutamate receptors. Annu Rev Neurosci 17:31-108.

Huh CY, Danik M, Manseau F, Trudeau LE, Williams S (2008) Chronic exposure to nerve growth factor increases acetylcholine and glutamate release from cholinergic neurons of the rat medial septum and diagonal band of Broca via mechanisms mediated by $\mathrm{p} 75^{\mathrm{NTR}}$. J Neurosci 28:1404-1409.

Ishii K, Wong JK, Sumikawa K (2005) Comparison of alpha2 nicotinic acetylcholine receptor subunit mRNA expression in the central nervous system of rats and mice. J Comp Neurol 493:241-260.

Israël M, Lesbats B, Bruner J (1993) Glutamate and acetylcholine release from cholinergic nerve terminals, a calcium control of the specificity of the release mechanism. Neurochem Int 22:53-58.

Konnerth A, Keller BU, Ballanyi K, Yaari Y (1990) Voltage sensitivity of NMDA-receptor mediated postsynaptic currents. Exp Brain Res 81:209-212.

Lavoie B, Parent A (1994) Pedunculopontine nucleus in the squirrel monkey: distribution of cholinergic and monoaminergic neurons in the mesopontine tegmentum with evidence for the presence of glutamate in cholinergic neurons. J Comp Neurol 344:190-209.

Li WC, Soffe SR, Roberts A (2004) Glutamate and acetylcholine corelease at developing synapses. Proc Natl Acad Sci U S A 101:15488-15493.

Lindström S, Schomburg ED (1973) Recurrent inhibition from motor axon collaterals of ventral spinocerebellar tract neurons. Acta Physiol Scand 88:505-515.

Matsubayashi H, Alkondon M, Pereira EF, Swanson KL, Albuquerque EX (1998) Strychnine: a potent competitive antagonist of alphabungarotoxin-sensitive nicotinic acetylcholine receptors in rat hippocampal neurons. J Pharmacol Exp Ther 284:904-913.

Matsubayashi H, Inoue A, Amano T, Seki T, Nakata Y, Sasa M, Sakai N (2004) Involvement of alpha7- and alpha4beta2-type postsynaptic nicotinic acetylcholine receptors in nicotine-induced excitation of dopaminergic neurons in the substantia nigra: a patch clamp and single-cell PCR study using acutely dissociated nigral neurons. Brain Res Mol Brain Res 129:1-7.

McCrea DA, Pratt CA, Jordan LM (1980) Renshaw cell activity and recurrent effects on motoneurons during fictive locomotion. J Neurophysiol 44:475-488.

Mentis GZ, Alvarez FJ, Bonnot A, Richards DS, Gonzalez-Forero D, Zerda R, O’Donovan MJ (2005) Noncholinergic excitatory actions of motoneurons in the neonatal mammalian spinal cord. Proc Natl Acad Sci U S A 102:7344-7349.

Moroni M, Zwart R, Sher E, Cassels BK, Bermudez I (2006) Alpha4beta2 nicotinic receptors with high and low acetylcholine sensitivity: pharmacology, stoichiometry, and sensitivity to long-term exposure to nicotine. Mol Pharmacol 70:755-768.

Nickerson Poulin A, Guerci A, El Mestikawy S, Semba K (2006) Vesicular glutamate transporter 3 immunoreactivity is present in cholinergic basal forebrain neurons projecting to the basolateral amygdala in rat. J Comp Neurol 498:690-711.

Nishimaru H, Restrepo CE, Ryge J, Yanagawa Y, Kiehn O (2005) Mamma- 
lian motor neurons corelease glutamate and acetylcholine at central synapses. Proc Natl Acad Sci U S A 102:5245-5249.

Renshaw B (1941) Influence of discharge of motoneurons upon excitation of neighboring motoneurons. J Neurophysiol 4:165-183.

Renshaw B (1946) Central effects of centripetal impulses in axons of spinal ventral roots. J Neurophysiol 9:191-204.

Schneider SP, Fyffe REW (1992) Involvement of GABA and glycine in recurrent inhibition of motoneurons. J Neurophysiol 68:397-406.

Song ZM, Hu J, Rudy B, Redman SJ (2006) Developmental changes in the expression of calbindin and potassium channel subunits Kv3.1b and Kv3.2 in mouse Renshaw cells. Neuroscience 139:531-538.

Traynelis SF (1998) Software-based correction of single compartment series resistance errors. J Neurosci Methods 86:25-34.

Wanaverbecq N, Semyanov A, Pavlov I, Walker MC, Kullmann DM (2007)
Cholinergic axons modulate GABAergic signaling among hippocampal interneurons via postsynaptic $\alpha_{7}$ nicotinic receptors. J Neurosci 27:5683-5693.

Woodhull AM (1973) Ionic blockage of sodium channels in nerve. J Gen Physiol 61:687-708.

Zhang J, Berg DK (2007) Reversible inhibition of GABAA receptors by alpha7-containing nicotinic receptors on the vertebrate postsynaptic neurons. J Physiol 579:753-763.

Zhang ZW, Coggan JS, Berg DK (1996) Synaptic currents generated by neuronal acetylcholine receptors sensitive to alpha-bungarotoxin. Neuron 17:1231-1240.

Zwart R, Vijverberg HP (1998) Four pharmacologically distinct subtypes of alpha4beta2 nicotinic acetylcholine receptor expressed in Xenopus laevis oocytes. Mol Pharmacol 54:1124-1131. 